\title{
Fluorescent sensing of maleate versus fumarate by a neutral cyclohexane based thiourea receptor $\dagger$
}

\author{
Ana M. Costero, ${ }^{*}$ Manuel Colera, Pablo Gaviña and Salvador Gil \\ Received (in Cambridge, MA, USA) 28th October 2005, Accepted 1st December 2005 \\ First published as an Advance Article on the web 5th January 2006 \\ DOI: $10.1039 / b 515320 d$
}

A new cyclohexyl based fluorescent anion receptor, is able to recognize maleate versus fumarate both as their TMA salts.

Construction of fluorescent sensors for specific anions is a particularly attractive research area. A fluorescent sensor for anions can be built following the binding site-signalling unit approach by attaching an appropriate photoactive fluorophore to a specific anion receptor. ${ }^{1}$ Urea and thiourea subunits are currently used in the design of neutral receptors for anions, owing to their ability to act as H-bond donors, ${ }^{2}$ and many ligands containing either one or two of these groups have been reported to be excellent carboxylate receptors and sensors for carboxylate anions. $^{3}$

Among the fluorescent mechanisms developed for the signalling process in anion sensing, excimer/exciplex formation has been successfully used. ${ }^{4}$ As excimer formation is strongly dependent on geometry, the binding unit has to be carefully designed. Cyclohexane derivatives with the appropriate configuration have been demonstrated to be useful in recognition processes and it has been perfectly established that the rigidity of this system can control the complex geometry. ${ }^{5}$

During several years we have been studying the complexing properties of ligands derived from trans-transoid-trans 1,2,4,5tetrasubstituted cyclohexanes and their possible application in sensing. ${ }^{6}$ Now we would like to report the preparation of two new cyclohexane based ligands, $\mathbf{1}$ and $\mathbf{2}$, both as racemic mixtures, and their utility in the selective recognition of maleate (3) versus fumarate (4) anions (Chart 1). These ligands have been designed in such a way that they could be easily transformed into the corresponding ditopic ligands by modifying the substituents on the ester moieties (for example by including coronands instead of ethyl groups).

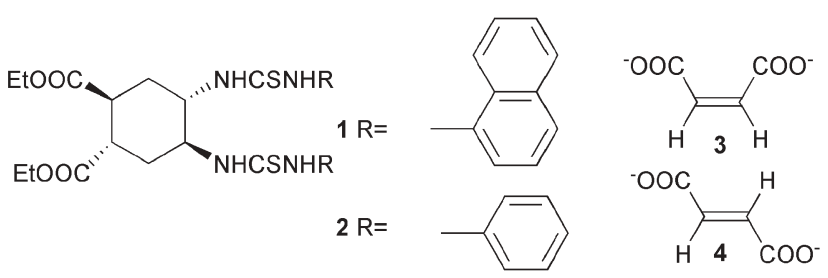

Chart 1

Department of Organic Chemistry. Universidad de Valencia, 46100 Burjassot, Valencia, Spain. E-mail: Ana.Costero@uv.es;

Fax: +34 963543152; Tel: +34 963544410

$\uparrow$ Electronic supplementary information (ESI) available: Complex stoichiometries, fluorescence, UV and ${ }^{1} \mathrm{H}$ NMR spectra. See DOI: 10.1039 b515320d
The interest in selective sensors able to distinguish maleate versus fumarate is not only related to $\pi$-diastereoisomer recognition but is also due to the different biological behaviour of these anions. In fact, whereas fumarate is generated in the Krebs cycle, maleate is a well known inhibitor of this cycle and its implication in different kidney diseases has been widely described. ${ }^{7}$

Ligands 1 and 2 were prepared from trans-1,2-bis(methoxycarbonyl)-4-cyclohexene ${ }^{6 a}$ as shown in Scheme 1. The relative configuration of the stereocentres in these ligands was perfectly established by NMR techniques.t The preferred conformation of these ligands in DMSO solution was studied by ${ }^{1} \mathrm{H}$ NMR (see supplementary material $\dagger$ ). As shown in Fig. 1, ligands $\mathbf{1}$ and $\mathbf{2}$ present the cyclohexane moiety mainly in a chair conformation, both thiourea groups are in the equatorial positions and both ester groups in the corresponding diaxial disposition. In addition, modelling studies carried out by using PCModel $8.0^{10}$ showed that this conformation corresponds to a relative minimum of energy.

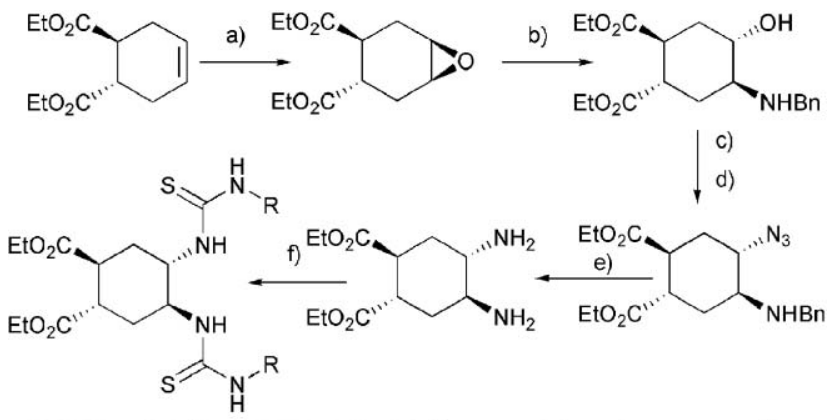

a) $\mathrm{MCPBA}, \mathrm{CH}_{2} \mathrm{Cl}_{2} 54 \%$; b) $\mathrm{BnNH}_{2}, \mathrm{LiClO}_{4}$, acetonitrile, reflux, $16 \mathrm{~h}, 93 \%^{8}$; c) $\mathrm{Ph}_{3} \mathrm{P}, \mathrm{DIAD}$, dry $\mathrm{THF}_{1}, 90 \%{ }^{8}$; d) $\mathrm{TMSN}_{3}$, dry acetonitrile, rt, $95 \%{ }^{9}$; e) $\mathrm{H}_{2}, \mathrm{Pd}(\mathrm{C}), \mathrm{EtOH}, 48 \mathrm{~h}, 95 \%$; f) RNCS, THF, reflux, 18h, R=Ph $97 \%$, $\mathrm{R}=$ Napht $84 \%$

Scheme 1

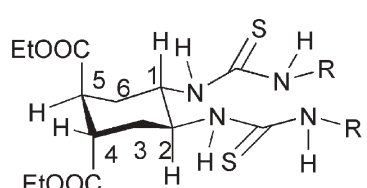

(a)

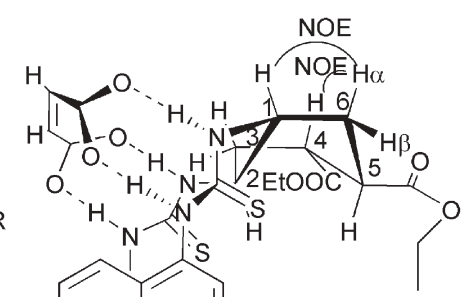

(b)
Fig. 1 (a) Conformation of ligands 1 and 2 in DMSO solutions. (b) Structural proposal for the complex formed between ligand $\mathbf{1}$ and TMA maleate. 
Complexation studies with maleate (3) and fumarate (4) both as their tetramethylammonium (TMA) salts were carried out using different techniques (UV, ${ }^{1} \mathrm{H}$ NMR and fluorescence spectroscopy). The stoichiometry of the complex with both ligands was always $1: 2$ for fumarate and $1: 1$ for maleate independently of the technique used. The values of the complexation constant ${ }^{11}$ calculated by using ${ }^{1} \mathrm{H}$ NMR are reflected in Table 1 and are similar to those obtained by using other methods (see supplementary material $\dagger$ ).

Fluorescence studies carried out with these ligands in the presence of increasing amounts of maleate and fumarate anions showed that ligand $\mathbf{1}$ is able to act as a selective sensor for maleate (3) versus fumarate (4) in DMSO solutions. Thus, the fluorescence spectrum for ligand $1\left(\lambda_{\text {exc. }}=290 \mathrm{~nm}\right)$ shows only one band at $410 \mathrm{~nm}$ with vibronic-band fine structure but no excimer band was observed which can be related to the high steric hindrance of the naphthalene moiety which precludes their parallel disposition. ${ }^{12}$

After the addition of increasing amounts of TMA fumarate (4) only a small quenching of the fluorescence was observed (Fig. 2a). By contrast the addition of TMA maleate (3) results in a new band at $495 \mathrm{~nm}$ (Fig. 2b). The intensity of this new band could be related to the formation of an excimer species. Both the different fluorescence behaviour and complex stoichiometries observed with $\mathbf{3}$ and $\mathbf{4}$ can be related to the ligand stereochemistry that gives rise to different geometries depending on the anion stereochemistry. Thus, the maleic dianion with its cis configuration perfectly fits into the complex inducing a conformational change in the ligand. This change places both naphthalene groups close and almost parallel which gives rise to the excimer emission. By contrast, the fumaric anion with a trans disposition of the carboxylate moieties is unable to form the $1: 1$ complex and two molecules are bound to the ligand, one in each thiourea group. This type of complexation does not induce changes in the ligand conformation and only a small quenching of the fluorescence is observed.

Table 1 Stoichiometry and $\log \beta$ in DMSO for ligands 1 and 2 with TMA fumarate and maleate by ${ }^{1} \mathrm{H}$ NMR

\begin{tabular}{llllll}
\hline & \multicolumn{2}{l}{ TMA fumarate } & & \multicolumn{2}{l}{ TMA maleate } \\
\cline { 2 - 3 } \cline { 5 - 6 } Ligand & $\log \beta_{2}$ & $\mathrm{~L}: \mathrm{A}$ & & $\log \beta_{1}$ & $\mathrm{~L}: \mathrm{A}$ \\
\hline $\mathbf{1}$ & $2.48 \pm 0.07$ & $1: 2$ & & $2.88 \pm 0.07$ & $1: 1$ \\
$\mathbf{2}$ & $4.39 \pm 0.06$ & $1: 2$ & & $5.1 \pm 0.9$ & $1: 1$ \\
${ }^{a} \mathrm{~L}=$ ligand, $\mathrm{A}=$ anion. & & & \\
\hline
\end{tabular}

The difference between both guests is also observed in the UV spectra. Thus, maleate salt gives rise to a shoulder at higher wavelength that is not present when fumarate was added to the ligand solution (see supplementary material $\dagger$ ).

The fluorescence of ligand $\mathbf{2}$ is very poor and only small modifications were observed after addition of both maleate and fumarate salts (similar results were also observed in the UV spectra). Data shown in Table 1 indicate that the complexes formed with ligand $\mathbf{2}$ are stronger than those formed with ligand $\mathbf{1}$; however, the small size of the phenyl groups present in $\mathbf{2}$ allows the maleate anion to fit in the cavity without large structural modification. This lack of conformational change would explain the small changes observed in the fluorescence spectra.

Two dimensional NMR studies have been carried out to give information about the conformation of the complexes formed by ligand $\mathbf{1}$ in DMSO solutions with both anions $\mathbf{3}$ and $\mathbf{4}$, and the results agree with the proposed geometries obtained by modelling using PCModel 8.0. Thus, in samples prepared with ligand $\mathbf{1}$ ( 1 equiv.) and tetramethylammonium maleate (1.5 equiv.) a set of signals corresponding to the $1: 1$ complex was observed along with weak signals attributable to the free ligand. In the complex the cyclohexyl moiety is far from the chair conformation and a twisted-boat or even a boat conformation agrees better with the observed results. Thus, COSY experiments show a strong correlation between $\mathrm{H} 6 \alpha$ and $\mathrm{H} 6 \beta$; $\mathrm{H} 6 \alpha$ also exhibits a clear correlation with $\mathrm{H} 5$ whereas coupling with $\mathrm{H} 1$ is weaker. $\mathrm{H} 6 \beta$ also exhibits a weak correlation with H5. In addition, NOESY experiments show that $\mathrm{H} 6 \alpha$ correlates with $\mathrm{H} 1$ and $\mathrm{H} 4$ whereas H6 $\beta$ only exhibits a weak correlation with $\mathrm{H} 5$. The signals corresponding to $\mathrm{H} 2$ and $\mathrm{H} 5$ are too close to allow observation of the NOE correlation. With all this information a structural proposal like that shown in Fig. $1 \mathrm{~b}$ can be acceptable. This structural proposal also would explain the fluorescence properties observed with this anion because in this complex both aromatic systems lay almost parallel allowing excimer formation.

By contrast, COSY experiments carried out with the same ligand and tetramethylammonium fumarate showed the clear chair conformation of the cyclohexyl moiety. Thus, COSY experiments showed the same correlation pattern as the free ligand and the NOESY experiments are also quite similar to the free ligand; the proton corresponding to the fumarate moiety shows a very small correlation with an aromatic proton at $7.55 \mathrm{ppm}$.

Studies carried out in DMSO-water mixtures (95:5) showed that the fluorescence response is clearly modified. Thus, after addition of TMA maleate, the band at $378 \mathrm{~nm}$ in the fluorescence
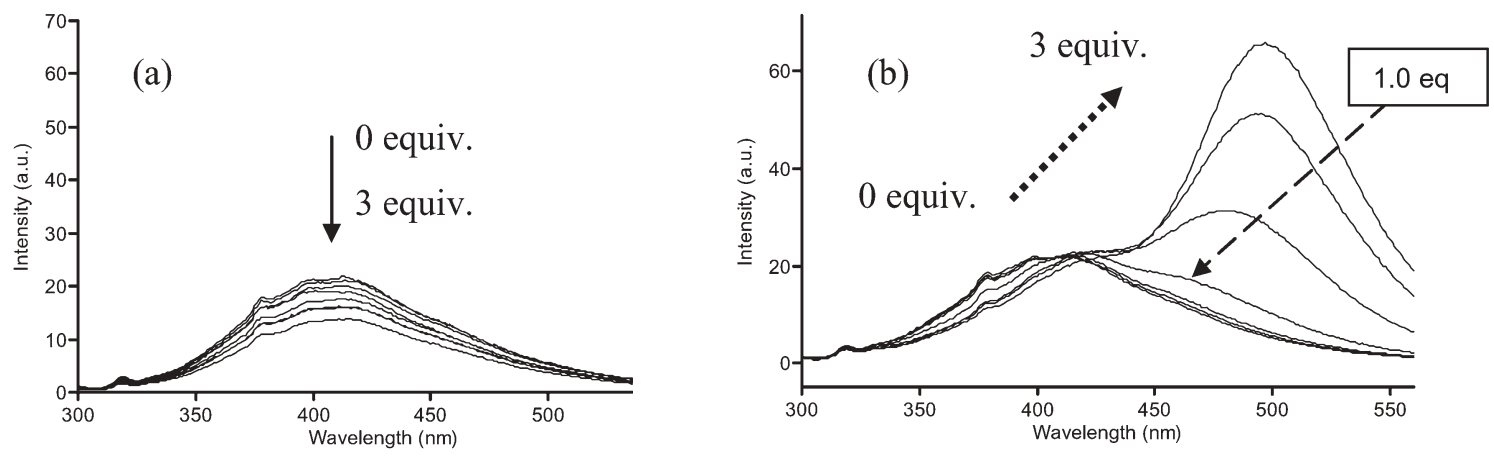

Fig. 2 Fluorescence spectra in DMSO (a) $1+$ TMA fumarate, (b) $1+$ TMA maleate $\left(\lambda_{\mathrm{exc}}=290 \mathrm{~nm}\right)$. 


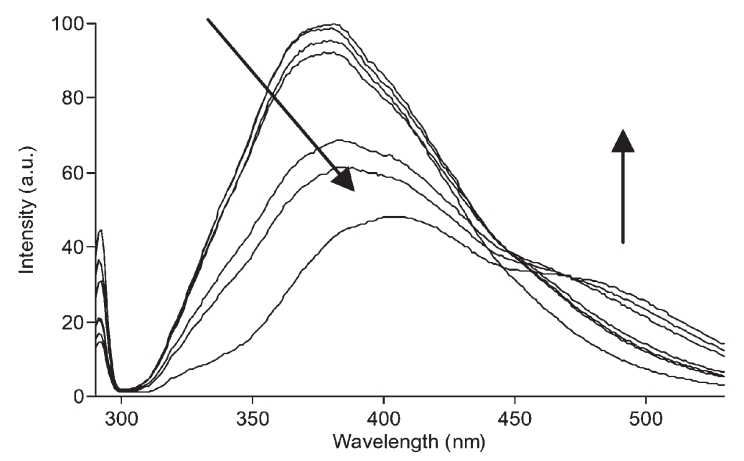

Fig. 31 + TMA maleate in DMSO-water $(95: 5)\left(\lambda_{\mathrm{exc}}=290 \mathrm{~nm}\right)$.

spectrum of ligand 1 shows a red shift in addition to a clear quenching. In addition the excimer emission is weaker than in the absence of water but still observable (Fig. 3). Under these conditions, ${ }^{1} \mathrm{H}$ NMR studies showed that the proportion of complex/free ligand present in solution is smaller than in anhydrous conditions, but the complex is even present at $60{ }^{\circ} \mathrm{C}$. The decrease in the complex concentration observed in the presence of water can explain the smaller excimer emission observed under these conditions.

In conclusion ligand $\mathbf{1}$ acts as a selective fluorescent sensor for maleate versus fumarate in DMSO even in the presence of $5 \%$ water. The selectivity is due to the conformational change in the cyclohexane moiety induced by the $1: 1$ complexation with maleate. Fumarate, with a trans configuration is able to be complexed by the ligand but the complexation does not give rise to the necessary conformational change.

The present research has been financed by Spanish DGCYT (PPQ2002-00986) and Generalitat Valenciana (Grupos 03/206). PG acknowledges Spanish MCYT for a Ramón y Cajal contract. $\mathrm{MC}$ also acknowledges the Spanish Government for a $\mathrm{PhD}$ grant. Finally, SCSIE (Universidad de Valencia) is gratefully acknowledged for all the equipment employed.

\section{Notes and references}

+ Ligand 1: ${ }^{1} \mathrm{H}$ NMR (300 MHz, DMSO-d $\left.{ }_{6}\right): \delta 7.94-7.91(\mathrm{~m}, 8 \mathrm{H}), 7.88$ $7.49(\mathrm{~m}, 8 \mathrm{H}), 6.29-6.27(\mathrm{~m}, 2 \mathrm{H}), 4.50-4.37(\mathrm{~m}, 2 \mathrm{H}), 4.15-4.11(\mathrm{~m}, 4 \mathrm{H}), 3.02$ (br. s, 2H), 2.44-2.40 (m, 2H), 1.51-1.39 (m, 2H), $1.25(\mathrm{t}, J=7.2 \mathrm{~Hz}, 6 \mathrm{H})$. COSY: strong correlation occurs between $\mathrm{H} 1,2$ and $\mathrm{H} 3,6$ axials and between H4,5 and H3,6 equatorial and less intense with H3, 6 axial. In addition, the signals corresponding to $\mathrm{N}-\mathrm{H}$ can be assigned as the signal at 8.2 correlates with $\mathrm{H} 1,2$. NOESY experiments show correlation between $\mathrm{H} 1,2$ and $\mathrm{H} 3,6$ both axial and equatorial positions with similar intensities. A similar result for $\mathrm{H} 4,5$ could be supposed for the conformation described. No correlation is found for the methylene except its correlation with the methyl group. Besides correlation is found for $\mathrm{H} 1,2$ and both the $\mathrm{NH}(8.2 \mathrm{ppm})$ and one aromatic $(7.55 \mathrm{ppm}) .{ }^{13} \mathrm{C}$ NMR (75 MHz, DMSO$\left.\mathrm{d}_{6}\right): \delta 181.6,173.0,134.9,130.1,129.2,128.8,127.5,127.0,126.2,125.9$, 122.3, 61.5, 40.4, 14.4. FAB-HRMS calcd. for $\mathrm{C}_{34} \mathrm{H}_{36} \mathrm{~N}_{4} \mathrm{O}_{4} \mathrm{~S}_{2}=628.2178$; found $=627.5624$. Ligand 2: ${ }^{1} \mathrm{H}$ NMR $\left(300 \mathrm{MHz}, \mathrm{DMSO}_{\mathrm{d}}\right) \delta 9.51(\mathrm{~s}$, $2 \mathrm{H}), 8.00(\mathrm{~s}, 2 \mathrm{H}), 7.49(\mathrm{~d}, J=12.8 \mathrm{~Hz}, 4 \mathrm{H}), 7.29(\mathrm{t}, J=12.8 \mathrm{~Hz}, 4 \mathrm{H}), 7.07$ (t, $J=12.8 \mathrm{~Hz}, 2 \mathrm{H}$ ), 4.52 (br. s, 2H), $4.09-4.00$ (m, 4H), 2.91 (br. s, $2 \mathrm{H}$ ), 1.99 (br. s, 4H), 1.20 (t, $J=7.2 \mathrm{~Hz}, 6 \mathrm{H}) .{ }^{13} \mathrm{C}$ NMR (75 MHz, DMSO-d 6 ): $\delta$ $179.3,173.3,139.8,128.8,124.1,126.5,61.16,52.11,31.29,21.61,14.18$. EIHRMS calcd. for $\mathrm{C}_{26} \mathrm{H}_{32} \mathrm{~N}_{4} \mathrm{O}_{4} \mathrm{~S}_{2}=528.1865$; found $=528.1882$.

1 (a) L. Fabbrizzi, M. Licchelli and G. Labaioli, Coord. Chem. Rev., 2000, 205, 85-108; (b) K. Nikura and E. V. Anslyn, J. Am. Chem. Soc., 1998, 120, 8533-8534; (c) A. Metzger and E. V. Anslyn, Angew. Chem., Int. Ed., 1998, 37, 649-652; (d) P. A. Gale, L. J. Twyman, C. I. Handlin and J. L. Sessler, Chem. Commun., 1999, 1851-1852; (e) P. Anzenbacher Jr., K. Jursíková and J. L. Sessler, J. Am. Chem. Soc., 2000, 122, 9350-9351; (f) S. Mizukami, T. Nagano, Y. Urano, A. Odani and K. Kikuchi, J. Am. Chem. Soc., 2002, 124, 3920-3925.

2 (a) P. A. Gale, Coord. Chem. Rev., 2003, 1-226; (b) P. D. Beer and P. A. Gale, Angew. Chem., Int. Ed., 2001, 486-516.

3 (a) R. J. Fitzmaurice, G. M. Kyne, D. Douheret and J. D. Kilburn, J. Chem. Soc., Perkin Trans. 1, 2002, 841-864; (b) A. J. Evans, S. E. Matthews, A. R. Cowley and P. D. Beer, Dalton Trans., 2003, 4644 4650; (c) H. Miyaji, S. R. Collinson, I. Prokes and J. H. R. Tucker, Chem. Commun., 2003, 64-65; (d) M. Barboiu, G. Vaughan and A. van der Lee, Org. Lett., 2003, 5, 3074-3076; (e) S. J. Brooks, P. A. Gale and M. E. Light, Chem. Commun., 2005, 4696-4698.

4 (a) S. Nishizawa, H. Kaneda, T. Uchida and N. Teramae, J. Chem. Soc., Perkin Trans. 2, 1998, 11, 2325-2328; (b) S. Nishizawa, H. Kaneda, Y. Kato and N. Teramae, J. Am. Chem. Soc., 1999, 121, 9463-9464.

5 (a) V. V. Samoshin, Mini-Rev. Org. Chem., 2005, 2, 225-235; (b) V. Amendola, M. Boiocchi, D. Esteban-Gómez, L. Fabrizzi and E. Monzani, Org. Biomol. Chem., 2005, 3, 2632-2639.

6 (a) A. M. Costero, J. P. Villarroya, S. Gil, M. J. Aurell and M. C. Ramirez de Arellano, Tetrahedron, 2002, 58, 6729-6734; (b) A. M. Costero, J. P. Villarroya, S. Gil, P. Gaviña and M. C. Ramirez de Arellano, Supramol. Chem., 2003, 15, 403-408.

7 (a) J. Stepinski, D. Pawlowska and S. Angielski, Acta Biochim. Pol., 1984, 31, 229-240; (b) A. Gougoux, G. Lemieux and N. Lavoie, Am. J. Physiol., 1976, 231, 1010-1017; (c) S. EiamOng, M. Spohn, N. A. Kurtzman and S. Sabatini, Kidney Int., 1995, 48, 1542-1548.

8 I. D. G. Watson and A. K. Yudin, J. Org. Chem., 2003, 68, 5160-5167.

9 (a) M. Chandrasekar, G. Sekar and V. K. Singh, Tetrahedron Lett., 2000, 41, 10079-10089; (b) Z. Li, M. Fernandez and E. N. Jacobsen, Org. Lett., 1999, 1, 1611-1613.

10 PCModel 8.0, Molecular modelling software for personal workstation, Serena Software, Bloomington, IN, http://www.serenasoft.com/ pcm8.html.

11 SPECFIT/32 III GLOBAL ANALYSIS SYSTEM, v.3.0, Spectrum Associates, Marlborough, MA, USA, www.bio-logic.info/rapid-kinetics/ specfit.html.

12 (a) R. Kraus, H-G. Weinig, M. Seydack, J. Bendig and U. Koert, Angew. Chem., Int. Ed., 2000, 39, 1835-1837; (b) H-G. Weinig, R. Krauss, M. Seydack, J. Bendig and U. Koert, Chem.-Eur. J., 2001, 7, 2075-2088. 